\title{
Genetic and Environmental Influences on the Ages of Drinking and Gambling Initiation: Evidence for Distinct Etiologies and Sex Differences
}

\author{
Leah S. Richmond-Rakerd, M.A. ${ }^{1,2}$, Wendy S. Slutske, Ph.D. ${ }^{1,2}$, Andrew C. Heath, Ph.D. ${ }^{2,3}$, \\ and Nicholas G. Martin, Ph.D. ${ }^{4}$ \\ ${ }^{1}$ University of Missouri Department of Psychological Sciences, Brisbane, Australia \\ ${ }^{2}$ Midwest Alcoholism Research Center, Brisbane, Australia \\ ${ }^{3}$ Washington University Department of Psychiatry, Brisbane, Australia \\ ${ }^{4}$ Queensland Institute of Medical Research, Brisbane, Australia
}

\section{Abstract}

\begin{abstract}
Aims-Investigate the genetic and environmental contributions to age at first drink (AFD) and age first gambled (AFG), assess their overlap and examine sex differences.

Design-Univariate twin models were fit to decompose the variation in AFD and AFG into additive genetic, shared environmental, and unique environmental factors. Bivariate genetic models were fit to assess the genetic and environmental contributions to the sources of covariation in AFD and AFG.
\end{abstract}

Setting-National Australian Twin Registry

Participants-4,542 same-sex and opposite-sex twins aged 32-43, $42 \%$ male and 58\% female

Measurements-AFD and AFG were assessed via structured psychiatric telephone interviews. Age of onset was treated as both continuous and categorical (early/late onset).

Findings-AFD and AFG were modestly correlated ( $r=.18)$. Unique environmental influences explained a substantial proportion of the variation in both AFD (.55, 95\% confidence interval $[\mathrm{CI}]=.50-.61)$ and $\mathrm{AFG}(.66,95 \% \mathrm{CI}=.59-.72)$, but these influences were uncorrelated $\left(r_{E}=.01\right)$. Additive genetic factors explained a notable proportion of variation in AFG $(.21,95 \% \mathrm{CI}=.003-$. 39), while shared environmental factors were important for AFD (.31, 95\% CI=.15-.46). Among men, genetic factors influenced variation in AFG but not in AFD and shared environmental factors influenced variation in AFD but not in AFG. Among women, shared environmental factors influenced variation in both AFD and AFG, but these environmental factors were not significantly correlated $\left(r_{C}=.09\right)$.

Conclusions-Among Australian twins, age at first drink and age first gambled are influenced by distinct unique environmental factors, and the genetic and environmental underpinnings of both phenotypes differ in men and women.

Corresponding author: Leah S. Richmond-Rakerd, Department of Psychological Sciences, University of Missouri, 210 McAlester Hall, Columbia, Missouri 65211, LR526@ mail.missouri.edu, Phone: (573) 882-6860, Fax: (573) 882-7710.

Conflicts of interest: None 


\section{Introduction}

Normative and problematic gambling and alcohol use co-occur [1] and often covary among adolescents [2]. This is of interest because early drinking and gambling onset is linked to future problems. Early drinking initiation predicts later alcohol dependence [AD; 3,4]. People with pathological gambling disorder report earlier ages of gambling onset than people without problems [5], and the severity of problem gambling in adolescence increases with decreasing age of initiation [6]. Finally, early-onset gamblers are more likely than lateonset gamblers to report past-year AD [7]. Despite these associations, no study to our knowledge has analyzed the association between drinking and gambling initiation.

Previous studies have assessed age of drinking onset from a behavioral genetic perspective. Agrawal et al. [8] found that age of initiation was modestly heritable (9-14\%). Employing a smaller number of twins from the same Australian sample, Sartor et al. [9] found that the heritability of AFD (defined as "late," "average," and "early") was 36\%, and demonstrated notable shared genetic influences on initiation and $\mathrm{AD}\left(r_{G}=0.59\right)$. In a sample of twins from Minnesota, McGue et al. [10] found that early alcohol use was more heritable in boys (55\%) than girls (11\%). To our knowledge, however, only one study has explored the genetic and environmental contributions to gambling initiation [11]. Employing a sample of twins from Minnesota, the researchers found that environmental factors explained most of the variance in early-onset gambling (gambling before age 18). However, the authors used a small sample, analyzed only a categorical variable, and did not assess the percentage of variation in initiation attributable to genetic and environmental factors.

The genetic and environmental overlap between drinking and gambling initiation is of interest given findings regarding the genetic liability to disordered gambling (DG) and alcohol dependence. Genetic and nonshared environmental factors each account for approximately $50 \%$ of the variation in $\mathrm{AD}$ [12]. Genes and unique environment each accounted for about half of the liability for both $\mathrm{DG}$ [13] and $\mathrm{AD}$ [14] in a cohort of Australian twins [13]. Regarding the covariation between DG and alcohol problems, genetic factors accounted for $75 \%$ of the overlap between problem gambling and DSM-III-R AD in a sample of US veteran male twins [15]. In a sample of Australian twins, genetic influences on continuous DSM-IV AD and DG phenotypes were more strongly correlated among men $\left(r_{G}=0.41\right)$ than women $\left(r_{G}=0.29\right.$ [16]). The genetic and environmental influences on earlylife substance involvement differ from those for problematic behaviors (e.g., drinking initiation is more influenced by shared environment than disordered use [12]). It is therefore of interest to assess whether the genetic and environmental covariation between early-onset drinking and gambling differs from the pattern previously observed with regard to problematic involvement. Investigating the etiology of gambling initiation and its relationship with drinking onset will facilitate understanding of how the genetics of gambling behaviors relate to those of co-occurring substance use phenotypes and inform developmental models of drinking and gambling involvement.

The present study investigated the genetic and environmental contributions to drinking and gambling initiation, assessed their genetic and environmental overlap, and tested for sex differences. Based on previous literature, we hypothesized that (1) the ages of drinking and gambling onset would be modestly and comparably heritable; (2) shared environmental influences would explain a significant proportion of the variance in drinking and gambling initiation; and (3) shared environment would explain a notable proportion of the overlap between the phenotypes. 


\section{Method}

\section{Participants}

Participants were 4,542 members of the Australian Twin Registry (ATR) Cohort II. In 1980-1982, a sample of 4,268 twin pairs born 1964-1971 were registered with the ATR, in response to appeals through the media and Australian school systems. They were first surveyed in 1989-1992 [17]. Data for the current study were collected in two subsequent waves of structured psychiatric telephone interviews. Respondents were queried about their age at first drink (AFD) during the first interview and their age first gambled (AFG) during the second interview. The first was conducted in 1996-2000 ( $n=6,265$ twins, mean age $=30.0$ years (range=24-36), response rate $=84.2 \%$; [14]), during which participants were administered the Semi-Structured Assessment for the Genetics of Alcoholism (SSAGA-OZ; [18]). The second was conducted in 2004-2007 $(n=4,764$ twins, mean age $=37.7$ years (range $=32-43$ ), response rate $=80.4 \%$ ) during which gambling behaviors were assessed [17]. Participants for the current study consisted of twins who participated in both waves. There were 1,705 complete twin pairs (809 MZ [494 female, 315 male], 896 DZ [328 femalefemale, 196 male-male, and 372 female-male]), 962 twins from incomplete pairs ( $287 \mathrm{MZ}$ [144 female, 143 male], 675 DZ [173 female-female, 209 male-male, and 293 femalemale]), and 170 twins from complete pairs where only one twin completed both interviews (58 MZ [32 male, 26 female], 112 DZ [31 male-male, 39 female-female, and 42 femalemale]).

\section{Procedure}

Interviews were conducted by trained lay-interviewers who were blind to the status of the cotwin. Informed consent was obtained from all participants and the study was approved by the Institutional Review Boards at Washington University School of Medicine (wave one), the University of Missouri (wave two), and the Queensland Institute of Medical Research (both waves).

\section{Measures}

Age of drinking onset-Lifetime abstainers constituted $1.2 \%$ of the sample and were coded as missing for analyses. Non-abstainers were asked, "How old were you the first time you had more than just a sip of beer, wine, or spirits?" Responses ranged from 1-35 years. To reduce the influence of low-lying values, following from [8], individuals reporting ages below 5 years were equated to 5 years. Mean ages for men and women were 15.4 years $(S D=2.7)$ and 16.2 years $(S D=2.5)$, respectively. A dichotomous variable representing early versus late drinking onset was also created. Following from [8,9], individuals who started drinking at or before age 14 were classified as early drinkers, and those who started drinking after age 14 were classified as late drinkers. $20.3 \%$ of the sample $(26.5 \%$ of men and $15.8 \%$ of women) was classified as early drinkers.

Retest data on AFD were collected 3.7 years $(S D=0.4$, range $=1.1-4.3)$ after the interview for a subsample of the twins. These data demonstrate good reliability in respondent recall $(r(166)=.80, p<.0001)$. Mean ages reported by the retest sample at Times 1 and 2 significantly differed $(t(165)=-2.33, p=.02)$; however, they differed by only 0.4 years (Time 1: $M=15.3$ years $(S D=2.9)$; Time $2: M=15.7$ years $(S D=2.9))$. Respondent reports at Time 1 were recorded as their AFD for analyses.

Age of gambling onset-Lifetime abstainers were $1.9 \%$ of the sample and were coded as missing for analyses. Non-abstainers were asked how old they were the first time they engaged in 11 different gambling activities. Table 1 displays the percentage of the sample, men, and women for which each activity represented their first gambling experience. This is 
of interest given that activities may be differentially accessible and more likely to be initiated at certain ages, and some may be disproportionately preferred among males and females. Individuals' earliest reported age was coded as their AFG. Responses ranged from 4-41 years. To reduce the influence of low-lying values, individuals who reported ages below 7 years were equated to 7 years. Mean ages for men and women were 17.3 years $(S D=3.6)$ and 18.3 years $(S D=4.3)$, respectively. A dichotomous variable representing early versus late gambling onset was also created. Individuals who started gambling before age 18 (the legal gambling age in Australia[19]) were classified as early gamblers, and those who started gambling at or after age 18 were classified as late gamblers. $33.7 \%$ of the sample (42.1\% of men and $27.6 \%$ of women) was classified as early initiators. $34.5 \%$ of individuals started gambling at age 18 , which was a considerably greater percentage than any other age.

Retest data for AFG were collected 3.4 months $(S D=1.4$, range=1.2-9.5) after the interview for a subsample of the twins. Respondents' reports at Times 1 and 2 were highly correlated $(r(163)=.75, p<.0001),{ }^{1}$ and mean ages reported by the retest sample at Times 1 and 2 did not significantly differ $(t(157)=1.51, p=.13)$. Mean AFG for the retest sample was 16.9 years $(S D=4.0)$ at Time 1 and 16.6 years $(S D=4.1)$ at Time 2 . These were lower than the samplewide average due to the retest study oversampling for individuals with gambling problems [17]. Respondent reports at Time 1 were recorded as their AFG for analyses.

To check for retrospective bias, correlations between individuals' ages at interview and their reported ages of onset were obtained. Correlations were .02 and .05 for AFD and AFG, respectively, indicating that older individuals did not report notably later ages of onset than younger individuals.

\section{Statistical Analysis}

Within-trait and cross-trait twin correlations were computed for continuous and categorical AFD and AFG. Tests of differences between correlations were performed to evaluate the evidence for genetic and environmental contributions to both phenotypes and their covariation. Qualitative sex differences (differences in the genes and/or shared environmental factors that influence a phenotype) were assessed by testing for differences between same-sex DZ and opposite-sex DZ correlations. Evidence for qualitative sex differences is present if opposite-sex DZ twin correlations are significantly lower than the corresponding same-sex DZ correlations.

Biometric models were fitted using the methods of maximum likelihood (for analysis of continuous phenotypes) and robust weighted least squares (for analysis of categorical phenotypes) directly to the raw twin data using Mplus (Version 6.1; [20]). Univariate biometric model-fitting was conducted to partition the variation in AFD and AFG, each considered separately, into additive genetic (A), shared environmental (C), and unique environmental $(\mathrm{E})$ influences, and to test for quantitative sex differences in the genetic and environmental contributions to AFD and AFG. Quantitative sex differences refer to differences in the magnitude of genetic, shared environmental, and unique environmental influences on a phenotype. Evidence for quantitative sex differences was tested by comparing the fits of models that allowed parameter estimates for men and women to vary with the fits of models that constrained estimates to be the same. Two bivariate genetic models (one for continuous and one for categorical phenotypes) were then fit to the data to

\footnotetext{
${ }^{1}$ Separate retest correlations for AFD and AFG were calculated for men and women and pooled via a Fisher's z-transformation to compute the overall correlation coefficient.
} 
assess the proportion of covariation in drinking and gambling initiation attributable to genetic, shared environmental, and unique environmental influences.

\section{Results}

\section{Associations Between Phenotypes}

Continuous AFD and AFG were modestly correlated, with the associations not differing by sex (men: $r=0.19, p<.0001$; women: $r=0.15, p<.0001 ; t(2789)=-.17, p=.87)$. There was a modest increase in the likelihood of gambling early as a function of drinking early, and again the relationships did not differ across sex (men: $\mathrm{OR}=1.96,95 \% \mathrm{CI}=1.58,2.42$; women: $\left.\mathrm{OR}=1.95,95 \% \mathrm{CI}=1.55,2.44 ; \chi^{2}=.-01, \mathrm{df}=1, p=.97\right) .65 .2 \%$ of the sample reported drinking first, $19.8 \%$ reported gambling first, and $11.9 \%$ reported starting both activities at the same age. Respondents who gambled first did so at age $13.3(S D=3.4)$ and started drinking at age $16.9(S D=2.6$; mean time interval=3.6 years $(S D=2.6))$. Individuals who drank first did so at age $15.3(S D=2.5)$ and started gambling at age $19.4(S D=3.4$; mean time interval=4.1 years $(S D=3.4)) .3 .2 \%$ of the sample was considered missing because they did not report on their AFD or AFG or abstained from both drinking and gambling. 13 individuals $(0.3 \%$ of the sample) abstained from both activities.

\section{Twin Correlations}

Univariate and bivariate twin correlations for continuous and categorical AFD and AFG and the results of tests of differences between correlations are presented in Table 2. Inspection reveals the following: (1) the within-trait MZ correlations for AFD and AFG were greater than the associated DZ correlations, implicating genetic factors in the etiology of both phenotypes; ${ }^{2}$ (2) the differences between the within-trait MZ and DZ correlations for both phenotypes were larger for men than women, implicating a stronger genetic contribution to AFD and AFG in males and a stronger shared environmental contribution to AFD and AFG in females; (3) the within-trait opposite-sex DZ correlations for continuous and categorical AFD were significantly smaller than the within-trait same-sex DZ twin correlations, implicating qualitative sex differences in the familial contributions to AFD; and (4) the cross-twin, cross-trait correlations for continuous phenotypes were larger for MZ than DZ twins, implicating genetic factors in the covariation between AFD and AFG.

\section{Biometric Model Fitting: Univariate Models}

For continuous AFD, A could be dropped from the model without a significant deterioration in fit $\left(\Delta \chi^{2}=1.88, \mathrm{df}=2, p=.39\right)$; however, $C$ could not be dropped $\left(\Delta \chi^{2}=13.97, \mathrm{df}=2, p<.001\right)$. For continuous AFG, there was a significant decrement in fit when A was dropped from the model $\left(\Delta \chi^{2}=7.23, \mathrm{df}=2, p=.03\right)$, but not when $\mathrm{C}$ was dropped $\left(\Delta \chi^{2}=5.42, \mathrm{df}=2, p=.07\right)$. Similar results were found for the categorical phenotypes.

\section{Sex differences}

Tests of sex differences were performed within the full models. For continuous AFD, parameters could be constrained individually, but constraining all of them resulted in a decrement in model fit $\left(\Delta \chi^{2}=10.94, \mathrm{df}=3, p=.01\right)$. For continuous AFG, additive genetic influences could be constrained $\left(\Delta \chi^{2}=2.2, \mathrm{df}=1, p=.14\right)$, but shared and unique environmental influences could not be constrained $\left(\mathrm{C}: \Delta \chi^{2}=4.73, \mathrm{df}=1, p=.03 ; \mathrm{E}: \Delta \chi^{2}=8.17\right.$, $\mathrm{df}=1, p<.01$ ). For categorical AFD, additive genetic and unique environmental influences could be constrained across sex, but constraining shared environmental factors resulted in a

\footnotetext{
${ }^{2}$ The only exception to this pattern was for categorical AFD, where the MZ female within-trait correlation (.60) was nearly identical to the associated DZ correlation (.59).
} 
decrement in model fit $\left(\Delta \chi^{2}=4.10, \mathrm{df}=1, p=.04\right)$. All parameters could be constrained for categorical AFG.

Standardized estimates of A, C, and E for the full sample, men, and women are presented for the full models in Table 3 and for continuous phenotypes for men and women in Figure 1. Inspection reveals that: (1) among men, additive genetic factors rather than shared environment explained much of the variance in AFG; (2) among women, shared and unique environmental influences explained most of the variance in AFD and AFG; and (3) the contribution of additive genetic, shared environmental, and unique environmental influences to both phenotypes was remarkably similar among women. (This effect is more notable for continuous measures, which is likely due to increased statistical power).

Bivariate Genetic Models-Bivariate models revealed two important findings regarding the covariation between drinking and gambling initiation: (1) Although unique environmental influences accounted for a substantial and comparable proportion of the variation in $\mathrm{AFD}$ and $\mathrm{AFG}$, these influences were uncorrelated $\left(r_{E}=.01,95 \% \mathrm{CI}=-.03, .05\right)$; and (2) among women, shared environmental factors explained a significant proportion of the variance in continuous AFD and AFG, but these factors were not significantly correlated $\left(r_{C}=.09,95 \% \mathrm{CI}=-.17, .36\right)$. In addition, neither the genetic nor the shared environmental correlations for the full sample were significant $\left(r_{G}=.29,95 \% \mathrm{CI}=-.17, .75 ; r_{C}=.30,95 \%\right.$ $\mathrm{CI}=-.24, .85)$. Although it was not possible to discern whether the modest correlation between drinking and gambling initiation could be explained by shared genes or family environment, we can safely conclude that it was due to familial factors because the unique (non-familial) environmental influences on AFD and AFG were uncorrelated.

\section{Discussion}

The present study extended prior investigations of the genetic and environmental influences on the age of drinking initiation $[8,9]$ by assessing how these factors overlap with the genetic and environmental contributions to a largely unexplored phenotype: the age of gambling onset. Results indicated that: (1) unique environmental factors explained a significant and comparable proportion of variation in AFD and AFG, but were uncorrelated; (2) additive genetic factors explained a notable proportion of variation in AFG, while shared environment was important for AFD; (3) qualitative sex differences were present for AFD, such that the familial factors influencing variation differed in men and women; (4) among men, genetic factors influenced variation in AFG but not in AFD and shared environmental factors influenced variation in AFD but not in AFG; and (5) among women, shared environmental factors influenced variation in both AFD and AFG, but these factors were not significantly correlated.

The unique environmental influences on drinking and gambling initiation are distinct. This is interesting given that the legal age to gamble and purchase alcohol in Australia is 18 years $[19,21] .85 \%$ of individuals reported starting to drink and gamble at different times; therefore, it seems likely that the contextual factors surrounding their initiation differ. Adolescent gambling [22-24] and drinking [25] have distinct environmental predictors, including legal status and accessibility. A much greater percentage of this sample started drinking than gambling before the legal age, supporting the differential accessibility hypothesis. Other possible explanations include peer influences unique to each behavior and the potential for more accessible gambling activities to take place in contexts that do not include drinking. The most popular activities among Australian adolescents are lotteries, scratch tickets, betting on races/sports, and card games [26,27]; several of these are among the most common first activities in the current sample. Investigating how alcohol use is 
differentially associated with activities will help clarify how the environmental influences on drinking and gambling initiation differ.

It is interesting to compare this with the finding that the unique environmental influences on DSM-IV alcohol dependence and disordered gambling are moderately correlated $\left(r_{E}=0.32\right.$; [16]). As noted earlier, the genetic and environmental contributions to early-onset phenotypes differ from those that affect problems [12]. It appears that as individuals progress toward addiction, the unique environmental factors that affect alcohol and gambling involvement converge.

Environmental influences explained most of the variation in AFD, while genetic and unique environmental factors accounted for the variation in AFG. The finding that shared environment contributes to drinking initiation aligns with prior studies of substance use onset [12] and previous analyses of the current sample that considered AFD as a continuous [8] and a categorical [9] phenotype. In addition, both [9] and the current study determined that unique environment accounts for approximately half of the variance in AFD. The finding that genetic factors were more important for gambling initiation suggests that initiation of a potentially addictive behavior may occur in a different context than initiation of a potentially addictive substance.

We found evidence for qualitative sex differences in regard to AFD. To our knowledge, only one other study [28] has investigated qualitative differences using a continuous AFD measure; they did not find differences. Studies using categorical phenotypes ("yes/no" initiation measures) have produced mixed results. Some have found evidence for sexspecific shared environmental influences [29], while others have not [30,31]. These studies are analogous to our dichotomous initiation phenotype, for which we found evidence for qualitative differences. How does this compare with other drinking outcomes? Regarding frequency and quantity of drinking, qualitative sex differences have been observed in samples of Dutch and Finnish twins [29,30,32,33]. Regarding alcohol dependence, analyses of adult samples have found evidence for partially distinct [34] and overlapping influences [35]. In a sample of adolescents where AD was analyzed as a symptom count, evidence was found for sex-specific common environmental effects [36]. It seems that qualitative sex differences may be present for only some stages of the drinking career, and that the nature of these differences changes. Variation in findings is also likely due to differences in sample ages and operationalization of variables. More research employing continuous measures will clarify how genes and shared environmental factors might influence the sexes differently depending on whether age of onset is considered generally or early vs. late initiation is examined.

The magnitude of genetic and environmental influences on drinking and gambling initiation differed in men and women. Shared environment did not account for any variation in continuous AFG among men (.00), but explained a moderate proportion of variation among women (.28), indicating that familial context exerts greater influence over females' than males' decision to initiate gambling. Parents' gambling-related attitudes and behaviors influence adolescents' gambling involvement (see [37] for a review). Intervention efforts enacted at the family level should be sensitive to differences in parental influence on girls' and boys' decision to gamble. In addition, shared environmental influences explained a comparable proportion of variation in continuous AFD and AFG among women, but these influences were not significantly correlated $\left(r_{C}=.09\right)$. Interventions aimed at delaying drinking and gambling initiation may need to differ depending on gender and whether individuals are engaged in one or both behaviors. For instance, given the minimal shared environmental overlap among women, targeting different familial influences may be necessary to address their initiation of both risky behaviors. 


\section{Limitations}

It is unclear how these results will generalize to samples from other countries. In particular, the widespread availability of gambling in Australia might facilitate stronger environmental influences on first gambling involvement than would be observed elsewhere. Availability might also interact with genetic predisposition to facilitate early gambling onset. Second, we cannot be sure that results will generalize to non-self-selected samples. However, minimal differences have been found between twins from pairs where both individuals participated in the 1996-2000 interview and singletons whose cotwin did not participate, suggesting that it is reasonably representative [38]. Third, although retest reliabilities for AFD and AFG were good, there was variability in reports over time. Fourth, our assessment of gambling activities may not have been comprehensive (e.g., we did not assess ages of onset for playing video/computer games for money or for betting on illegal activities [18]. However, we assessed the most popular activities in Australia and among Australian adolescents. Finally, limited power in bivariate models with categorical phenotypes constrained our ability to determine how genetic and environmental contributions to early versus late initiation of drinking and gambling differed. Future studies with increased power will help clarify the relationship between early initiation of gambling and alcohol use.

\section{Acknowledgments}

This work was supported by National Institute of Mental Health grants MH66206 and National Institute on Alcohol Abuse and Alcoholism grants AA007728 and AA13526. We thank Dixie Statham, Bronwyn Morris, and Megan Fergusson for coordinating the data collection for the twins, and David Smyth, Olivia Zheng, and Harry Beeby for data management of the Australian Twin Registry. We thank the Australian Twin Registry twins for their continued participation.

\section{References}

1. Barnes GM, Welte JW, Hoffman JH, Tidwell MO. The co-occurrence of gambling with substance use and conduct disorder among youth in the United States. Am J Addiction. 2011; 20:166-173.

2. Barnes GM, Welte JW, Hoffman JH, Tidwell MO. Gambling, alcohol, and other substance use among youth in the United States. J Stud Alcohol Drugs. 2009; 70:134-142. [PubMed: 19118402]

3. DeWit DJ, Adlaf EM, Offord DR, Ogborne AC. Age at first alcohol use: a risk factor for the development of alcohol use disorders. Am J Psychiat. 2000; 157:745-750. [PubMed: 10784467]

4. Hingson RW, Heeren T, Winter MR. Age at drinking onset and alcohol dependence. Arch PediatAdol Med. 2006; 160:739-746.

5. Kessler RC, Hwang I, LaBrie R, Petukhova M, Sampson NA, Winters KC, et al. The prevalence and correlates of DSM-IV pathological gambling in the National Comorbidity Survey Replication. Psychol Med. 2008; 38:1351-1360. [PubMed: 18257941]

6. Rahman AS, Pilver CE, Desai RA, Steinberg MA, Rugle L, Krishnan-Sarin S, et al. The relationship between age of gambling onset and adolescent problematic gambling severity. J Psychiat Res. 2012; 46:675-683. [PubMed: 22410208]

7. Lynch WJ, Maciejewski PK, Potenza MN. Psychiatric correlates of gambling in adolescents and young adults grouped by age at gambling onset. Arch Gen Psychiat. 2004; 61:1116-1122. [PubMed: 15520359]

8. Agrawal AA, Sartor CE, Lynskey MT, Grant JD, Pergadia ML, Grucza R, et al. Evidence for an interaction between age at first drink and genetic influences on DSM-IV alcohol dependence symptoms. Alcohol Clin Exp Res. 2009; 33:2047-2056. [PubMed: 19764935]

9. Sartor CE, Lynskey MT, Bucholz KK, Madden PAF, Martin NG, Heath AC. Timing of first alcohol use and alcohol dependence: evidence of common genetic influences. Addiction. 2009; 104:15121518. [PubMed: 19686520]

10. McGue M, Iacono WG, Legrand LN, Elkins I. Origins and consequences of age at first drink. II. Familial risk and heritability. Alcohol Clin Exp Res. 2001; 25:1166-1173. [PubMed: 11515563]

11. Winters KC, Rich T. A twin study of adult gambling behavior. J Gambl Stud. 1998; 14:213-225. 
12. Dick, DM.; Prescott, C.; McGue, M. The genetics of substance use and substance use disorders. In: Kim, Y-K., editor. Handbook of Behavior Genetics. 1st edn.. Springer; New York, NY: 2009.

13. Slutske WS, Zhu G, Meier MH, Martin NG. Genetic and environmental influences on disordered gambling in men and women. Arch Gen Psychiat. 2010; 67:624-630. [PubMed: 20530012]

14. Knopik VS, Heath AC, Madden PAF, Bucholz KK, Slutske WS, Nelson EC, et al. Genetic effects on alcohol dependence risk: re-evaluating the importance of psychiatric and other heritable risk factors. Psychol Med. 2004; 34:1519-1530. [PubMed: 15724882]

15. Slutske WS, Eisen S, True WR, Lyons MJ, Goldberg J, Tsuang M. Common genetic vulnerability for pathological gambling and alcohol dependence in men. Arch Gen Psychiat. 2000; 57:666-673. [PubMed: 10891037]

16. Slutske WS, Ellingson JM, Richmond-Rakerd LS, Zhu G, Martin NG. Shared genetic vulnerability for disordered gambling and alcohol use disorder in men and women: evidence from a national community-based Australian twin study. Twin Res Hum Genet. 2013; 16:525-534. [PubMed: 23527679]

17. Slutske WS, Meier MH, Zhu G, Statham DJ, Blaszczynski A, Martin NG. The Australian twin study of gambling (OZ-GAM): rationale, sample description, predictors of participation, and a first look at sources of individual differences in gambling involvement. Twin Res Hum Genet. 2009; 12:63-78. [PubMed: 19210181]

18. Bucholz KK, Cadoret R, Cloninger CR, Dinwiddie SH, Hesselbrock VM, Nurnberger JI, et al. A new, semi-structured psychiatric interview for use in genetic linkage studies: a report on the reliability of the SSAGA. J Stud Alcohol Drugs. 1994; 55:149-158.

19. Purdie, N.; Matters, G.; Hillman, K.; Murphy, M.; Ozolins, C.; Millwood, P. Report to Gambling Research Australia: Gambling and young people in Australia. Department of Justice; State of Victoria: 2011.

20. Muthén, LK.; Muthén, BO. Mplus User's Guide: Sixth Edition. Los Angeles, CA: 1998-2010. Author

21. Cobiac L, Vos T, Doran C, Wallace A. Cost-effectiveness of interventions to prevent alcoholrelated disease and injury in Australia. Addiction. 2009; 104:1646-1655. [PubMed: 21265906]

22. Barnes GM, Welte JW, Hoffman JH, Dintcheff BA. Shared predictors of youthful gambling, substance use, and delinquency. Psychol Addict Behav. 2005; 19:165-174. [PubMed: 16011387]

23. Felsher J, Derevensky J, Gupta R. Lottery participation by youth with gambling problems: are lottery tickets a gateway to other gambling venues? Int Gambl Stud. 2004; 4:109-125.

24. Felsher J, Derevensky J, Gupta R. Lottery play amongst youth: implications for prevention and social policy. J Gambl Stud. 2004; 20:127-153. [PubMed: 15060330]

25. Paschall MJ, Grube JW, Kypri K. Alcohol control policies and alcohol consumption by youth: a multi-national study. Addiction. 2009; 104:1849-1855. [PubMed: 19832785]

26. Delfabbro P, Thrupp L. The social determinants of youth gambling in South Australian adolescents. J Adolescence. 2003; 26:313-330.

27. Delfabbro P, Lahn J, Grabosky P. Further evidence concerning the prevalence of adolescent gambling and problem gambling in Australia: a study of the ACT. Int Gambl Stud. 2005; 5:209_ 228.

28. Heath AC, Martin NG. Teenage alcohol use in the Australian Twin Register: genetic and social determinants of starting to drink. Alcohol Clin Exp Res. 1988; 12:735-741. [PubMed: 3064632]

29. Rose RJ, Dick DM, Viken RJ, Pulkkinen L, Kaprio J. Drinking or abstaining at age 14? A genetic epidemiological study. Alcohol Clin Exp Res. 2001; 25:1594-1604. [PubMed: 11707634]

30. Geels LM, Bartels M, van Beijsterveldt TCEM, Willemsen G, van der Aa N, Boomsma DI, et al. Trends in adolescent alcohol use: effects of age, sex and cohort on prevalence and heritability. Addiction. 2011; 107:518-527. [PubMed: 21831193]

31. Rhee SH, Hewitt JK, Young SE, Corley RP, Crowley TJ, Stallings MC. Genetic and environmental influences on substance initiation, use, and problem use in adolescents. Arch Gen Psychiat. 2003; 60:1256-1264. [PubMed: 14662558]

32. Koopmans JR, Boomsma DI. Familial resemblances in alcohol use: genetic or cultural transmission? J Stud Alcohol Drugs. 1996; 57:19-28. 
33. Viken RJ, Kaprio J, Koskenvuo M, Rose R. Longitudinal analyses of the determinants of drinking and of drinking to intoxication in adolescent twins. Behav Genet. 1999; 29:455-461. [PubMed: 10857250]

34. Prescott CA, Aggen SH, Kendler KS. Sex differences in the sources of genetic liability to alcohol abuse and dependence in a population-based sample of U.S. twins. Alcohol Clin Exp Res. 1999; 23:1136-1144. [PubMed: 10443978]

35. Heath AC, Bucholz KK, Madden PAF, Dinwiddie SH, Slutske WS, Bierut LJ, et al. Genetic and environmental contributions to alcohol dependence risk in a national twin sample: consistency of findings in women and men. Psychol Med. 1997; 27:1381-1396. [PubMed: 9403910]

36. Rose RJ, Dick DM, Viken RJ, Pulkkinen L, Kaprio J. Genetic and environmental effects on conduct disorder and alcohol dependence symptoms and their covariation at age 14. Alcohol Clin Exp Res. 2004; 28:1541-1548. [PubMed: 15597087]

37. McComb JL, Sabiston CM. Family influences on adolescent gambling behavior: a review of the literature. J Gambl Stud. 2010; 26:503-520. [PubMed: 20349270]

38. Heath AC, Howells W, Kirk KM, Madden PAF, Bucholz KK, Nelson EC, et al. Predictors of nonresponse to a questionnaire survey of a volunteer twin panel: findings from the Australian 1989 twin cohort. Twin Res Hum Genet. 2001; 4:73-80. 


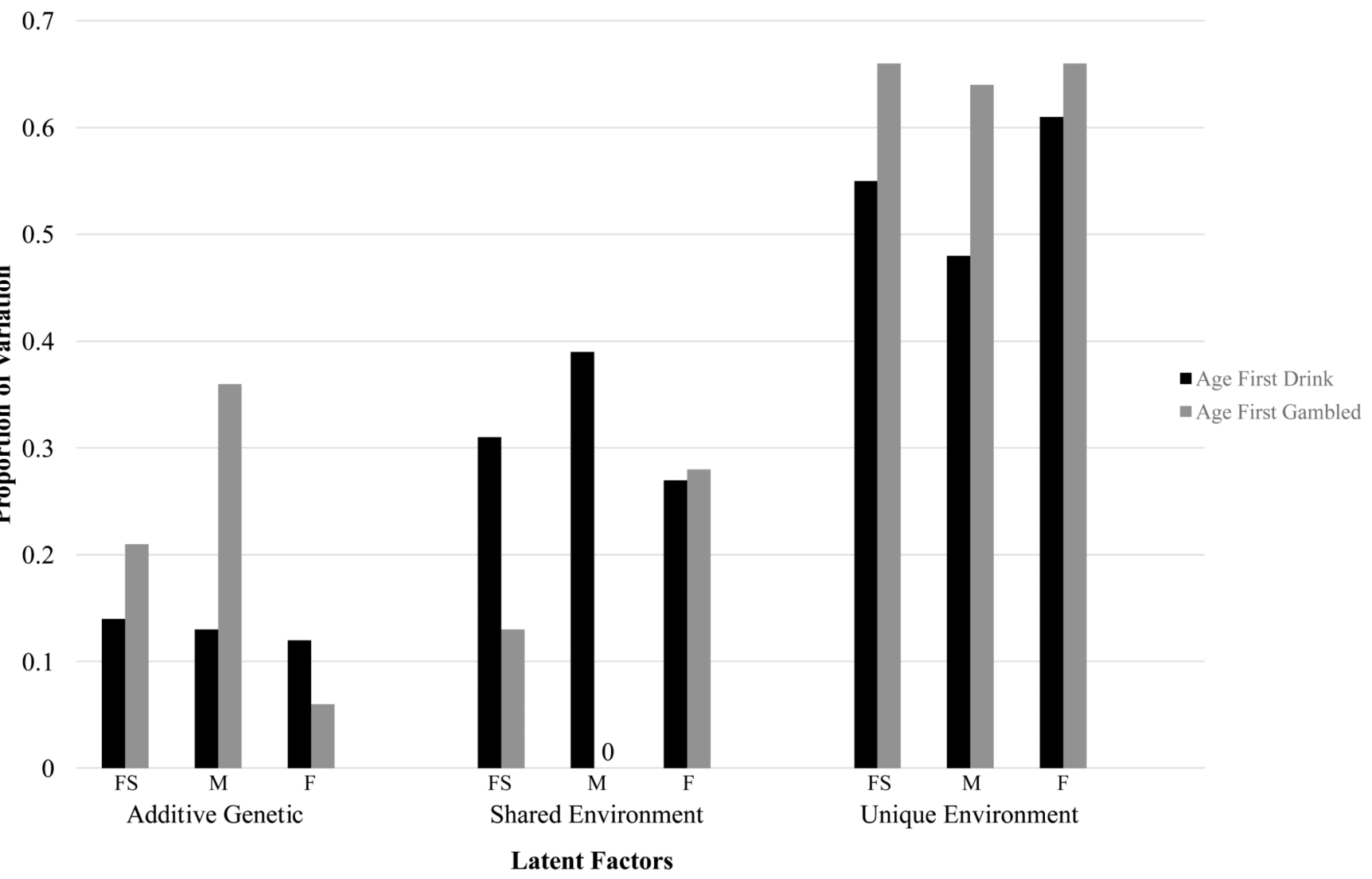

Figure 1.

Proportion of variation in continuous AFD and AFG in the full sample, men, and women accounted for by additive genetic, shared environmental, and unique environmental factors. $\mathrm{FS}=$ full sample, $\mathrm{M}=$ males, $\mathrm{F}=$ females. 


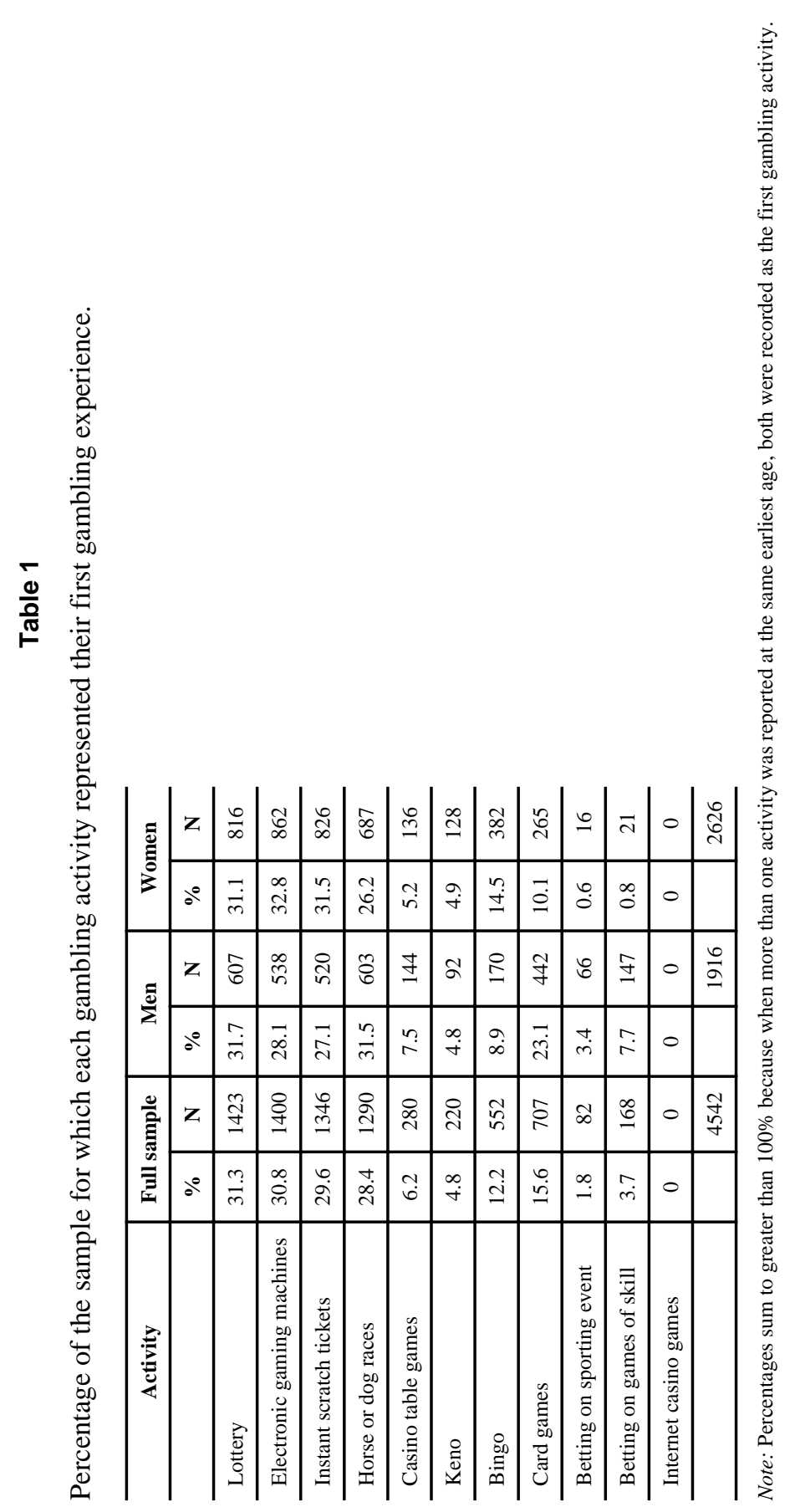




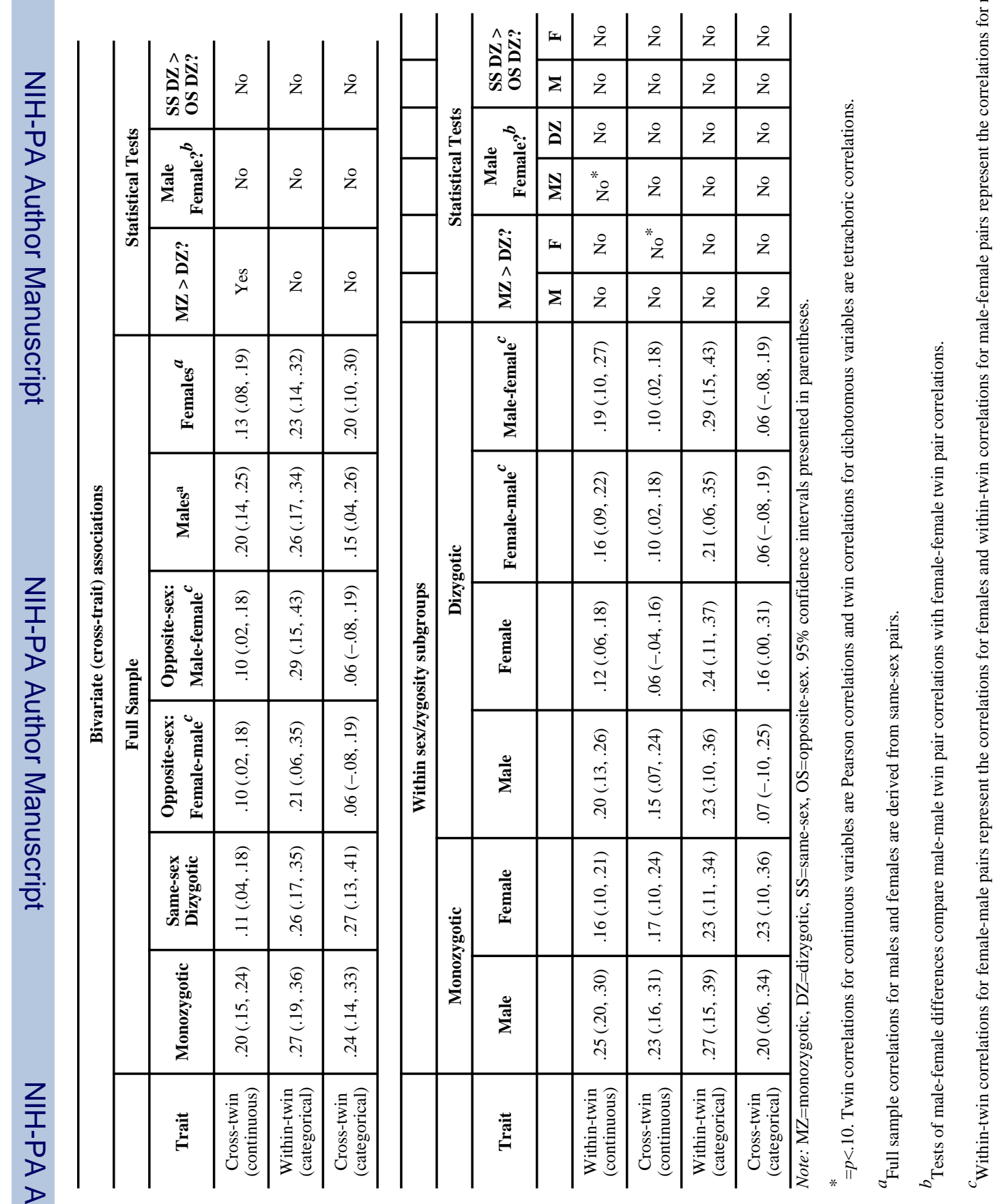




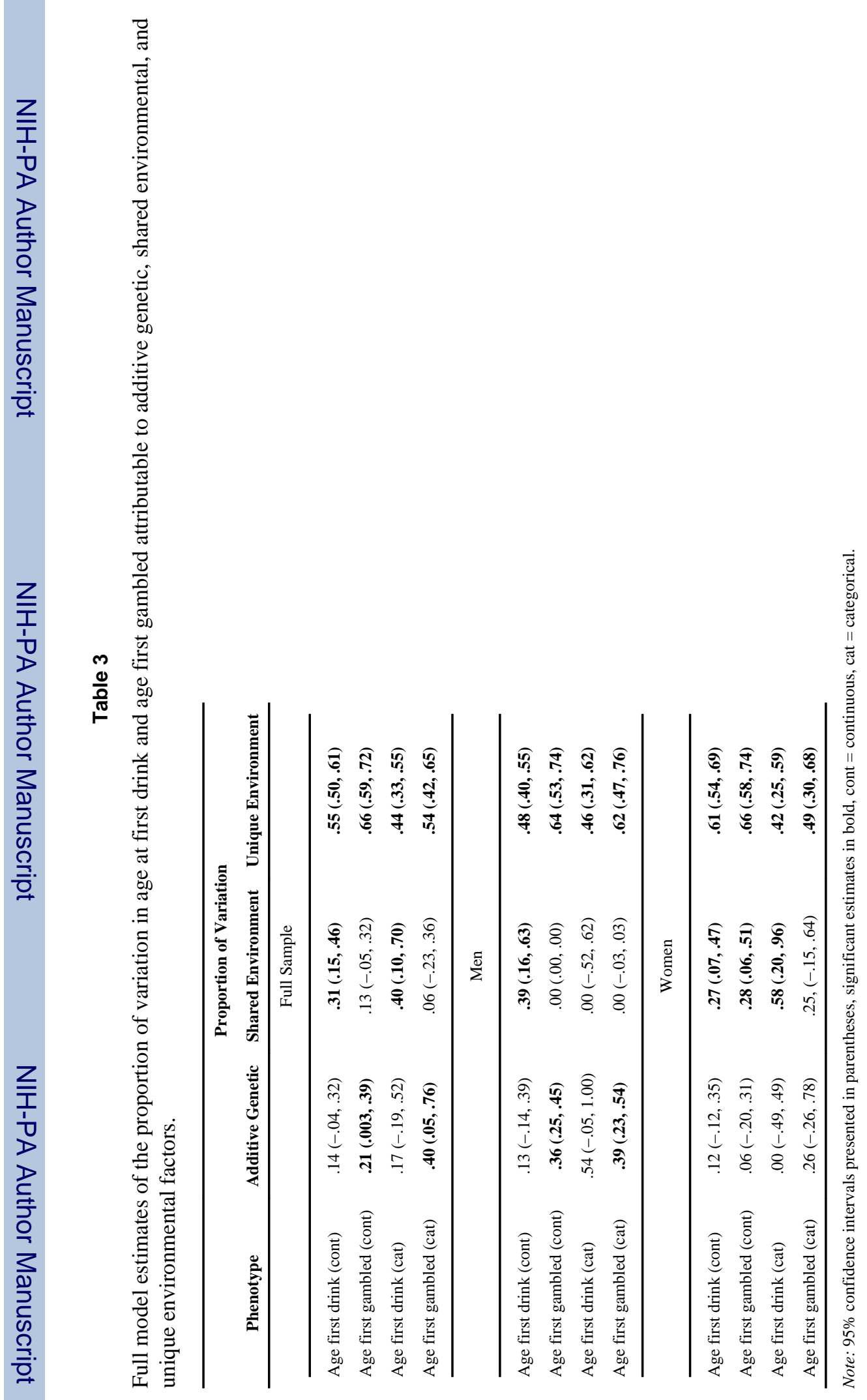

